Running Head: EMPIRICALLY TESTING A PSYCHOSOCIAL MODEL

The Decision of Out-of-Home Placement in Residential Care after Parental Neglect:

Empirically Testing a Psychosocial Model ${ }^{1}$

${ }^{1}$ This work was financially supported by an individual doctoral grant attributed to the first author by Portuguese National Science Foundation (FCT - ref. SFRH / BD / 25912 / 2005). 


\begin{abstract}
Out-of-home placement decisions in residential care are complex, ambiguous and full of uncertainty, especially in cases of parental neglect. Literature on this topic is so far unable to understand and demonstrate the source of errors involved in those decisions and still fails to focus on professional's decision making process. Therefore, this work intends to test a sociopsychological model of decision-making that is a more integrated, dualistic and ecological version of the Theory of Planned Behavior's model. It describes the process through which the decision maker takes into account personal, contextual and social factors of the Decisionmaking Ecology in the definition of his/her decision threshold.

One hundred and ninety five professionals from different Children and Youth Protection Units, throughout the Portuguese territory, participated in this online study. After reading a vignette of a (psychological and physical) neglect case towards a one-year-old child, participants were presented with a group of questions that measured worker's assessment of risk, intention, attitude, subjective norm, behavior control and beliefs towards residential care placement decision, as well as worker's behavior experience, emotions and family/childrelated-values involved in that decision.

A set of structural equation modeling analyses have proven the good fit of the proposed model. The intention to propose a residential care placement decision was determined by cognitive, social, affective, value-laden and experience variables and the perceived risk. Altogether our model explained $61 \%$ of professional's decision towards a parental neglect case. The theoretical and practical implications of these results are discussed, namely the importance of raising awareness about the existence of these biased psychosocial determinants.
\end{abstract}




\section{The Decision of Out-of-Home Placement in Residential Care after Parental Neglect: Empirically Testing a Psychosocial Model}

The decision to keep a child in the family or to put her in out-of-home placement following a case of parental maltreatment - has been characterized as complex, ambiguous and full of errors and uncertainty. In Portugal, like elsewhere, the law has been described as vague and as lacking in definitions of key concepts and terms to case assessment and decision-making (Banach, 1998; Gold, Benbenishty, \& Osmo, 2001; Rodrigues, 2012; Torres et al., 1998). The decision-making is even more difficult and uncertain for instances of parental neglect in which, although the long-term effects are detrimental (DePanfilis, 2006), the physical proofs are hard to obtain (Beckett, McKeigue, \& Taylor, 2007; Dickens, 2007; Rodrigues, 2012; Stowman \& Donohue, 2005). The invisibility of parental neglect behavior and of its immediate effects on the child makes it hard, not only for worker's assessment of it as maltreatment, but also to get a court-valid proof that can legally sustain decision-making. The lack of specific guidelines makes the decision-making process heavily susceptible to worker's subjectivity and interpretation. Furthermore, the uncertainty and ambiguity of the decision making context makes the workers more aware and afraid of institutional and social judgment, making them more likely to adopt self-defensive decisions and to postpone the intervention until a 'catapult' event occurs (Dickens, 2007; Torres et al., 1998). Therefore, there is a striking need to better understand the factors involved in the decision of out-ofhome placement of neglect children and how these factors relate to each other.

The study of decision-making factors in the child protection field has been mostly focused on variables of the child (e.g., age - Dagleish \& Drew, 1989), the parents and parenthood (e.g. cooperation, health problems - Davidson-Arad, Englechin-segal, \& Wozner, 2003; Zuravin \& DePanfilis, 1997), maltreatment characteristics (e.g., severity, chronicity - 
Dagleish \& Drew, 1989; Rossi, Schuerman, \& Budde, 1999) and of the family and social context (e.g., income; social support - Festinger, 1996; Fialkov \& Cohen, 1990; Zuravin \& DePanfilis, 1997). Despite the relevance assumed by all those case variables in out-of-home placement in residential care - particularly in risk assessment - those variables are only one part of this decision-making process equation (Baumann, Dalgleish, Fluke, \& Kern, 2011; Munro, 2005; Summers, Gatowski, \& Dobbin, 2012). The Decision Making Ecology framework adequately shows so by stating that, in the decision process, case risk assessment is combined with worker's factors and external and organizational factors for determining the threshold of action (Baumann et al., 2011; Dalgleish, 1988).

Although the lack of and need for studies on the role played by worker's psychosocial variables in the decision has been acknowledged for a long time (Belsky, 1991; Munro, 1999; Portwood, 1998), the great majority of the studies undertaken in this field still focus mostly on worker's socio-demographic variables (Arad-Davidzon \& Benbenishty, 2008). The few studies that attend on the role of worker's psychosocial variables focused on the role of worker's perception of the risk for and well-being of the child (e.g., Dalgleish \& Drew, 1989; Jagannathan \& Camasso, 1996; Sullivan, Whitehead, Leschied, Chiodo, \& Hurley, 2008) and of worker's attitudes in the decision-making process (Arad-Davidzon \& Benbenishty, 2008; Peters, 2001; Rodrigues, 2012; Shemmings, 2000). Nevertheless, those studies have mainly used qualitative methodologies or descriptive and simple statistical analysis of variable associations (Arad-Davidzon \& Benbenishty, 2008).

Moreover, research has not been able to demonstrate how the worker integrates multiple factors in the definition of his/her decision threshold, i.e. a personal 'line in the sand' that sustains an out-of-home placement decision (Baumann et al., 2011, p. 7; or decision proposal to be discussed in collective board decisions). Thus, considering all the arguments mentioned above, there is a need for the theoretical design and empirical test of psychosocial models that 
operationalize the process under which the worker integrates decision-making ecology factors and, thus, explain how the decision threshold is defined.

Accordingly, the goal of this paper is to present the test of a psychosocial model of the residential care placement decision-making process in the context of a parental neglect case, taking as a starting point theoretical models of behavior and decision-making predictions widely studied in Social Psychology (Ajzen, 1985).

\section{Decision-Making Topic Research and its Application to the Field of Child Protection}

Legal, institutional and social guidelines determine that the decision-making process should be sustained in a rational, objective and rigorous weighing of both benefits and negative effects of all available alternatives. One of the most known and validated rational models in the study of decision-making is the one from the Theory of Planned Behavior (Ajzen, 1985) which defines that an intention to take an action or undertake a certain behavior is predicted by the positive or negative attitude towards that behavior, as well as by the subjective norm (i.e. the influence others have on us), and the perceived behavior control over barriers to that behavior. In that model these predictors are in turn predicted by one's beliefs. This model has been applied to a variety of contexts such as the study of sexual behavior (e.g., Boldero, Moore, \& Rosenthal, 1992), health-related practices (e.g., Godin \& kok, 1996) or pro-environmental behavior (e.g., Castro, Garrido, Reis, \& Menezes, 2009). It has also been applied to ethical decisions like medical (Randall \& Gibson, 1991) or financial decisions (Buchan, 2005). In the field of child protection there is a team of researchers that has demonstrated the empirical utility of this model to explain child abuse reporting behavior among nurses and kindergarten teachers (Feng, Huang, \& Wang, 2010; Feng \& Wu, 2005). Nevertheless, to our knowledge, the model from the Theory of Planned Behavior has never 
been tested in the field of child protection workers' decision of out-of-home placement in residential care of children victim of parental neglect.

It can be assumed that the rational information processing that the theory of planned behavior model describes is the groundbase for every decision taken about out-of-home placement following parental maltreatment. Indeed, the decision should be a result of a deliberate and systematic assessment and evaluation of case information and it should be sustained on valid assessment tools (Rzepnicki \& Johnson, 2005; Schwalbe, 2004) and on legal and socio-political criteria (Backe-Hansen, 2003).

Nevertheless, inconsistencies both between and within workers assessments and decisions (e.g., Britner \& Mossler, 2002; Peters, 2001), as well as errors and biases (e.g., partial use of available information, lack of long-term perspective and lack of attention to family history; Munro, 1999), have been found in the decision-making process. Also, the recognition that worker's judgment, assessments and actions are determined both by their legal, theoretical and organizational knowledge and by their personal and professional experiences raised the hypothesis of the effect of emotional, experiential and value-laden variables in risk assessment and out-of-home placement decision (e.g., Davidson-Arad et al., 2003; Summers et al., 2012; Taylor, Beckett, \& McKeigue, 2008).

These common influences suggest an information processing that is not purely rational, and denotes the presence of intuitive and automatic processes that give the decision-making process an obscure, 'irrational' (Rzepnicki \& Johnson, 2005) and random character (Lindsey, 1991). This type of heuristic, intuitive or automatic information processing, identified by decision making researchers in the last decade of the twentieth century, brought to light the limits of rationality and the role of complementary processes, i.e. the recognition of a cognitive process that produces a response without using a conscious, logic and step-by-step process (Hammond, 1996). 
Nowadays the main perspective is the one that accepts the co-existence of both types of cognitive processes and, thus, allow for the conciliation of rational and heuristic perspectives - the so-called dual-process models (Eagly \& Chaiken, 1993; Gerrard, Gibbons, Houlihan, Stock, \& Pomery, 2008). Also in child protection literature, the importance of adopting an integrative and dual perspective that considers the co-existence of these two cognitive dimensions of human beings as part of the same continuum has been acknowledged (Munro, 2005; Rzepnicki \& Johnson, 2005). Accordingly, it is pertinent to consider the information processing underlying decision making in general and out-of-home placement decisions for child protection in particular, in the design and test of an adequate model.

Adding to that, the literature from the Theory of Planned Behavior model and child protection (Baumann et al., 2011) highlights the importance of developing more ecological models through the inclusion of variables specifically pertinent for the behavior/decision under study. Therefore, this study intends to test a psychosocial model of out-of-home placement decision-making that, as is described below, is a more integrative, dual and ecologic version of Theory of Planned Behavior's model.

\section{Proposed model: Psychosocial decision-making model of out-of-home placement in residential care for parental neglect cases}

The proposed model, based on Theory of Planned Behavior model, hypothesizes that worker's motivation to decide for the out-of-home placement in residential care of a neglected child (Intention) is predicted by the positive or negative evaluation of that decision (Attitude), as well as by the influence others have on worker's decision (Subjective Norm) and the control worker's perceive to have over barriers to that decision (Perceived Behavior Control). These three predictors are in turn each predicted by worker's beliefs about the decision, and about its social and legal/institutional context, i.e. beliefs about consequences of residential 
care placement (e.g., family reorganization; child suffer after being removed from the family), beliefs about others opinions (e.g., work superiors; judges of child and family court; public opinion), and beliefs about what are the barriers to residential care placement (e.g. case overload; competencies and skills) (Figure 1).

[Insert Figure 1]

Furthermore, in order to impute to it an intuitive and behavior-specific character other variables were added. The choice of those variables was based on their pertinence for out-ofhome placement decision (e.g., Davidson-Arad et al., 2003; Summers et al., 2012; Taylor, Beckett, \& McKeigue, 2008) and also on empirical evidence that demonstrates its effects and added-value in explaining other ethical behavior (Conner \& Armitage, 1998; Ajzen, 1991; Ajzen \& Fishbein, 2005; Weber \& Johnson, 2009; Oreg \& Katz-Gerro, 2006; Milfont, Duckitt, \& Wagner, 2010; Eagly \& Chaiken, 1993; Conner \& Armitage, 1998). Therefore, the proposed model also considers the, direct or indirect, effect of worker's value-laden, affective (Emotions) and experiential variables (Behavior Experience), as well as risk-danger assessment.

The inclusion of value-laden variables in the model is due to the relevance that for long has been given to their role as determinants of conceptual conflicts (Epstein, 1980), especially in social policy issues (Tetlock, 1986). In the context of child protection, cultural values are considered to determine, not only the perception of good and bad/(in)adequate parental practices and the assessment of risk, but also the type of social responses implemented in the prevention and protection of children (Rodrigues, 2012). Particularly, the presence of ambivalence and conflict in child protection worker's judgment has been associated with the dilemma that results from the conflict between the value of the child (i.e. the valuation of the best interest of the child, his/her rights and well-being) and the value of the family (i.e. the valuation of preserving family ties/bonds and family privacy; e.g., Goldstein, Solnit, 
Goldstein, \& Freud, 1996). The presence of these values (and the conflict between them) seems to be instituted both by a cultural, social and, thus, informal process (Portwood, 1998), and by a legal formal process, through the intervention principles of 'Best Interest of the Child' and 'Prevalence of the Family' dictated by the Portuguese law (Law n¹49/99, Art. $\left.\mathrm{n}^{\circ} 4\right)$. Besides this direct and explicit reference in the law there are reasons to believe that workers are aware of the role of values and the conflict between them in their judgment (Rodrigues, 2012).

In turn, the inclusion of emotions have been considered particularly important in the study of risk decisions, especially when negative consequences and feelings can result from it (Conner \& Sparks, 2005; Gerrard et al., 2008). Therefore, anticipated emotions, i.e. emotions typically not immediately experienced but that are expected to be experienced after the behavior (Loewenstein, Weber, Hsee, \& Welch, 2001), are particularly pertinent in risk decisions. In child protection, the effect of worker's emotions on out-of-home placement decision has been associated with the impossibility to simultaneously respond to child, family and worker's own interests (Besharov, 1985; Goldstein et al., 1996; Taylor et al., 2008). Thus, for one hand, it can be inferred that such emotions might result from worker's believes about the consequences that, based on his/her past experience, each social response (residential care vs. kept-at-home) will have for the child and the family (e.g., Tilbury \& Osmond, 2006). On the other hand, it can also be assumed that such emotions can result from the risk of social and institutional criticism and recrimination towards the worker that might result from normative and social influence processes following an erroneous decision (either residential care placement or keep the child at home; e.g., Dickens, 2007; Kanani, Regehr, \& Bernstein, 2002; Lachman, \& Bernard, 2006; Munro, 2005). It can also be assumed that the beliefs about the quality and constrains of social responses (e.g., lack of vacancies; lack of parental 
intervention programs; quality of the services) can determine the good or bad consequences attributed to residential care placement decision (e.g., Kenny, 2001).

The impact of Behavior Experience on future behavior's intention has been understood as resulting, either from a habit or automatic response that follows behavior repetition or from unchanged/constant cognitive and motivational factors that determine the behavior every time it occurs (Ajzen \& Fishbein, 2005). In fact, it has been designated as Theory of Planned Behavior's efficacy and Sufficiency Measure as the direct effect between past and future behavior points to the lack of important variables in the model (Ajzen, 1991). The impact of behavior experience in child protection literature - mostly operationalized in term of years of experience (e.g., Davidson-Arad et al., 2003) - has been linked in decision making to the influence it may have in: 1) worker's perceptions and practical knowledge of barriers towards residential care placement and worker's beliefs about its consequences for the child (Davidson-Arad et al., 2003; Summers et al., 2012); as well as 2) a better worker's consciousness over institutional and social criticism and pressures that may follow a residential care placement decision (Dickens, 2007; Kanani et al.,2002; Lachman, \& Bernard, 2006; Munro, 2005).

Lastly, legal and theoretical guidelines determine that, following a child maltreatment event, state intervention should be sustained by a rigorous risk assessment of the case (Davidson-Arad, 2009; Humphreys \& Ramsey, 1993; Parton, 2010; Law nº147/99, Art. 3. ${ }^{\text {) }}$. Thus, the assessment of whether child well-being is at risk or in danger will determine if and what kind of intervention is needed (Rossi et al., 1999; Davidson-Arad, 2009; Law nº147/99). Theoretically, a child is at risk when the child has not yet got to or developed an undesirable condition (negative consequences), but when the child has, in relation to his/her peers, a greater probability to have so (Cichetti \& Rizley, 1981; Little, Axford, \& Morpeth, 2004; Parton, 2010). In turn, a child is considered to be in danger when a threat is imminent or when 
there is already harm to the child and his/her well-being and integrity are compromised (Parton, 2010). The terms risk and danger correspond therefore to different levels of the same theoretical concept (Cichetti \& Rizley, 1981; Parton, 2010). Because those different levels presuppose different types of social responses, and having in mind that the distinction of these terms is not always clear, consensual and free of subjectivities, both levels should be considered in the evaluation of a maltreatment case. Although its direct effect on intention/behavior is the most acknowledged (e.g., pro-environmental behavior - Oreg \& Katz-Gerro, 2006), Slovic and collaborators (Slovic, Peters, Finucane, \& MacGregor, 2005) also hypothesized an indirect effect that translates a reaction to risk that implies an analysis i.e. the management of risk through logic, reason and scientific deliberation.

The literature review above described allowed for the definition of a set of hypothesis that sustain the model presented in Figure 1. This study goal is to test the adequacy of this psychosocial and dual model for predicting child protection workers' decision of out-of-home placement decision for neglected children.

\section{Methods}

\section{Participants}

The sample comprised 195 professional workers from 150 Portuguese Children and Youth Protection Units, randomly selected. These units had at the time about 1250 professionals and therefore a response rate of $15.5 \%$ can be estimated. The mean age of the workers was 38.4 years $(S D=9.20)$, ranging from 23 to 64 . Most of them were female (84.7\%), married or lived together (73.6\%) and had one child $(\mathrm{M}=1.17, \mathrm{SD}=1.03)$. Furthermore, $83.1 \%$ held a college degree, mainly in Social Work (32.6\%), Psychology $(22.0 \%)$ and Education $(12.1 \%)$. The mean years of professional experience was $14.14(\mathrm{SD}=$ 9.38) and of professional experience in Child protection field/cases was $4.03(\mathrm{SD}=3.20)$. The 
study included professionals from all different regions of Portuguese territory (main land and archipelagos) (Table 1).

[Insert Table 1]

\section{Measurement}

The 'Questionnaire of Residential Care Placement Decision Making' (Rodrigues, 2012), was specifically developed to predict the following specific behavior: to propose the residential care placement decision (action) of at-risk/danger child (target) next time (time) the worker is faced with a case similar to the one presented (context). The questionnaire contains a vignette representing a (psychological and physical) neglect case (fictitious but presented as real) towards a one-year-old child, with information, presumably, gathered from the child's health center, day care facility and neighbors (Figure 2). [Insert Figure 2]

Additionally the questionnaire is composed by 13 sets of items that operationalize the proposed model's variables.

Intention is measured by two items related to the probability of participants motivation to defend the decision among the professional team members - Next time I'm presented with a case similar to this one I will make an effort / attempt to defend a residential care placement decision. Items are scored in a 7-point bipolar Likert scale from -3 unlikely to 3 likely. The two items reveal a moderate to high internal reliability $($ Pearson Correlation $=.77)$.

Attitude is measured by asking the participants to complete the following phrase: 'To defend a residential care placement decision the next time I'm presented with a case similar to this one, will be for the child something ...' The phrase is to be completed in terms of how negative-positive and how prejudicial-beneficial they evaluate the out-of-home placement decision for the at-risk child. These two items are evaluated in bipolar Likert scales (from -3 
negative/prejudicial to 3 positive/beneficial). The measure reveals a high reliability (Pearson Correlation $=.82$ )

Subjective Norm is measured by three items evaluated in 7-point Likert scales (from 1 very unlikely to 7 very likely). The items refer to the probability that significant others will support worker's decision - Next time I'm presented with a case similar to this one the majority of people that are important to me will think it is the right thing to do / approve the decision / like the decision to defend a residential care placement decision. The Cronbach's Alpha of .92 indicates a strong internal reliability.

Perceived Behavior Control measure includes two items about the level of difficulty and level of trust related to the decision - To defend a residential care placement decision I'm presented with a case similar to this one will be possible to implement / is something with which I will feel confident about. Each of the items is evaluated in a 7-point bipolar Likert scale from -3 disagree to 3 agree. The low internal reliability of the measure suggested the elimination of one of the items to increase the alpha. Therefore, the final measure includes the first two items, with a moderate internal reliability $($ Pearson Correlation $=.43)$.

Anticipated Emotions are measured with four items and each of the items includes two antagonistic emotions (e.g., sad-happy). The participants are asked to report how much defending a residential care placement decision would elicit the positive or the negative emotion of each item - To defend a residential care placement decision next time I'm presented with a case similar to this one will make me feel worried-relaxed / sad-happy / good-bad / unsatisfied-satisfied. The items are measured in a bipolar Likert scale (from -3 to 3) in which each of the emotions corresponds to one of its opposite end points. The items reveal moderate to high reliability level $(\alpha=.83)$. 
Behavior Experience is measured by one item that asks how often do you defend a residential care placement decision for cases similar to the one presented. This item is assessed in a 7-point unipolar Likert scale - from 1 never to 7 always.

Perception about the Value of Family and Perception about the Value of the Child are each measured by one item taken from the European Values Study (2008) - respectively, A child can only be happy when living with a mother and a father and It's the parents' duty to do the best for their children, even if it compromises their own well-being. The participants' level of agreement with the items is assessed in a 7-point unipolar Likert scale.

Risk/Danger Assessment is measured by an index risk-danger created by the sum of two items, each one assessing either the level of risk or danger that the worker thinks the neglect case represents to the child - How would you evaluate this case in terms of risk / danger). The items are evaluated in 7-point unipolar Likert scales (from 1 low to 7 high) but before index construction they were recoded from 0 to 6 , and thus the final measure range from $0-12$. The items reveal a moderate reliability level (Pearson Correlation $=.52)$.

Behavioral beliefs are assessed by two composite measures, one concerning positive impacts of residential care placement on the child and on the family ( 8 items - e.g., Child protection; Give the family time to recover and reorganize) and the other concerning negative impacts (9 items - e.g., Penalize the child by removing her/him from the family context; Parents' disregard for the child). Each belief item was evaluated in terms of how negativepositive and how likely it is for it to occur following a residential care placement decision. The composite measures of behavioral beliefs resulted from the sum of the product of each belief item strength (likelihood to occur) and evaluation (negative-positive) - to simplify the reading of results, the analysis considered the squared root of that value after recoding the items into a unipolar scale. The two composite variables revealed good reliability levels $(.72<$ $\alpha<.89$ ). Nevertheless, a factorial analysis confirmed the existence of the two (positive and 
negative) composite measures and supported the factorial validity of the measure (Rodrigues, 2012).

Normative Beliefs measure addresses the following significant others as potential influential sources: 1) Others in the professional context with whom the professional works directly (2 items - e.g., work superiors); 2) Others in the professional context with whom the professional doesn't work directly (4 items - e.g., judges of child and family court); 3) Others from the worker's personal network and the broader social context (3 items - e.g., Portuguese people - public opinion). In the questionnaire the participants are asked to evaluate each of these sources in terms of its strength - i.e. the likelihood of those "others" approving the participant's decision to defend a residential care placement decision - and in terms of its motivation - i.e. participant's willingness to act in accordance to the opinion of each of those significant others. Both dimensions are evaluated in a 7-point bipolar Likert scale and each normative belief resulted from the multiplication of the value of the two dimensions (Ajzen, 1991) - to simplify the reading of results, the analysis considered the squared root of that value after recoding the items into a unipolar scale (1-7). A factorial analysis supported the existence of three highly correlated measures (Rodrigues, 2012). The three composite variables revealed good reliability levels $(.86>\alpha<.91)$.

Behavior Control Beliefs are measured by 14 item beliefs related to 1) Resources Availability (8 items - e.g., Amount of case files that are my responsibility) and 2) Characteristics and reliability of the available information and self-trust (6 items - e.g., Trust in my competencies and skills). In the questionnaire the participants are asked to evaluate each of the items in terms of its strength - i.e. the likelihood that each item occurrence would impact on worker's residential care placement decision - and in terms of its power - i.e. the likelihood of having control over each factor. Both dimensions are evaluated in a 7-point bipolar Likert scale and each Perceived Behavior Control belief resulted from the 
multiplication of the value of the two dimensions (Ajzen, 1991) - to simplify the reading of results, the analysis considered the squared root of that value after recoding the items into a unipolar scale. The two composite variables revealed good reliability levels $(.75<\alpha<.83)$. Nevertheless, a factorial analysis supported the factorial validity of the measure (Rodrigues, 2012).

The questionnaire was pre-tested by child protection experienced professionals and was revised by and discussed with different independent researchers.

\section{Procedure}

The study was undertaken with the approval and collaboration of the National Child and Youth Protection Committee. After randomly selecting 150 child protection units throughout the country, assuring a balanced representation of the different country regions, the President of the National Committee sent an e-mail to all 150 At-risk Child and Youth Protection Units' coordinators asking them to forward the e-mail to all professionals. In the e-mail, professionals were invited and encouraged to participate in the study and a link was given to complete a questionnaire online. Prior to completing the questionnaire, participants were presented to specific legal and operational information to be kept in mind during this task, they were also asked to confirm that they had read the information and to give their individual consent to participate in the study.

\section{Data Analysis Plan}

We used structural equation modeling with latent variable to estimate the parameter of the model. The analyses were performed using AMOS software and they were first undertaken for study sample on the basis of items variances-covariance matrix (Table 2). Missing values were dealt with by using the ad hoc pairwise deletion method. To ensure the 
statistical identification of the measure model, one item of each latent variable was constrained to 1.00 . Moreover, in order to avoid negative error variance when only two items were available to measure one latent variable, the loadings of these items were constrained to equality. Finally, error variance of latent variables measured with only one item were constrained to zero (Bollen, 1989). Initially, we estimated the parameters of the model according to the method of maximum likelihood. Then, in order to verify possible type 2 error in each parameter due to the sample size, we re-estimated the models by using boostrapping procedure with 1000 resampling. Both analysis provided equal results, and therefore original maximum likelihood estimates are here presented. Criteria for acceptable model fit were a goodness of fit (GFI), an adjusted goodness of fit (AGFI) and a comparative fit index (CFI) greater than .90, as well as a root mean square error of approximation (RMSEA) of .06 or less (Bentler, 1990; Bentler \& Bonett, 1980; Byrne, 2001; Kline, 2005), a standardized root mean square residual (SRMR) less than 0.10 (Hu \& Bentler, 1998) and a relative chi-square value $\left(\chi^{2} / \mathrm{df}\right)$ lower than 3 (Kline, 2005).

[Insert Table 2]

\section{Results}

\section{Model Goodness of Fit}

The proposed model reveals good indexes of fit in terms of the ratio $\chi^{2} / \mathrm{df}$, CFI and standardized RMR value and acceptable in terms of GFI, AGFI and RMSEA (Table 3). Therefore, the analysis proves the good fit of the proposed model for explaining the residential care placement decision when there is a case of parental neglect. Table 3 also shows that the proposed model has better fit indexes than the model in which only Theory of Planned Behavior's effects were estimated (Ajzen, 1985), and thus is more suitable to explain the decision. Moreover, the model here proposed explains $61 \%$ of the Intention and, thus, the 
results confirm that the inclusion of worker's emotions, experience, values and risk/danger assessment contributes to explain more $14 \%$ of the variance of Intention explained by Theory of Planned Behavior's model (47\%).

[Insert Table 3]

\section{Model Description: direct effects}

The test of the proposed model reveals that worker's Intention (I) to defend the residential care placement of a neglected child is mainly predicted by the worker's positive evaluation of that behavior (Attitude) but also by significant others' approval of that behavior (Subjective Norm) and by how much relevance the worker attributes to child's interests and protection (Value of Child; Figure 3). No reliable effects were found for Perceived Behavior Control (PBC), Value of Family, Risk/Danger Assessment and Behavior Experience on Intention.

\section{[Insert Figure 3]}

Furthermore, the Attitude towards residential care placement was predicted, not only by the consequences attributed to that decision (e.g., 'child protection', 'Parents' disregard for the child') but also by significant others' opinion (e.g., others from work, family and friends), by the emotions the worker anticipates to experience following that decision (e.g., worriedrelaxed; sad-happy), as well as by the value attributed to child protection and to family preservation. The more positive the consequences, the others opinions and the emotions related to the decision of placing the child in residential care, and the less the importance given to child protection and family preservation values, the higher the probability of proposing that decision. 


\section{Mediation Analyses: indirect effects}

Besides the above-mentioned direct predictors of worker's Intention, the proposed model also proves the existence of its indirect predictors through different mediators.

Firstly, as hypothesized based on Theory of Planned Behavior model, the behavioral and normative beliefs' effects on Intention are mediated by, respectively, the Attitude ( $\mathrm{Z}=$ 2.94, $\mathrm{p}<.05)$ and the Subjective Norm $(Z=3.00, \mathrm{p}<.05)$. Thus, the results show that the more positive the consequences the worker associates with the placement of a neglected child in residential care, the more positive will be the worker's attitude towards that decision; and that, the more the worker perceives social support from significant others - from work, family and friends -, the more will the worker sense social approval towards that decision, which, in turn, increases worker's Intention to defend it.

Secondly, the results reveal that worker's Attitude towards the decision, not only is the best direct predictor of worker's Intention, but also plays an important role as mediator of other variables' indirect effect on Intention. Besides Behavioral Beliefs mentioned above, the other three variables are: Emotions $(Z=3.44, \mathrm{p}<.05)$, Risk/Danger Assessment $(\mathrm{Z}=3.52, \mathrm{p}$ $<.05)$; and, additionally, Subjective Norm $(\mathrm{Z}=3.62, \mathrm{p}<.05)$. These mediation effects indicate that the Intention to defend the residential care placement of a neglected child is predicted by the positive evaluation of that behavior (i.e. Attitude), which in turn is predicted by significant others approval, positive emotions and by the worker's assessment of the case as high risk/danger. The indirect effect of Emotions on Intention is, in turn, preceded by the mediation effect of Emotions on the effect of Subjective Norm $(Z=2.05 ; \mathrm{p}<.05)$ and Behavior Experience $(Z=2.63 ; \mathrm{p}<.05)$ on worker's Attitude. No mediation effects were found in the relation between worker's Beliefs and Attitude. These results mean that the greater the worker's experience in proposing residential care placement of a neglected child 
and the greater the others approval, the more positive will be the emotions the worker anticipates to experience and the more positive will be the evaluation of the decision, i.e. worker's Attitude.

An indirect effect on Intention through the worker's Attitude also occurs between the Value of the Child $(Z=-2.36, p<.05)$ and the Value of the Family $(Z=-2.66, p<.05)$ and Intention. Both mediation effects indicate that the more the Value the worker attributes to child's protection and family preservation, the more negative will be the Attitude towards the residential care placement of the child and, in turn, the lower will be the worker's motivation (i.e. Intention to defend that decision). Only in the case of the Value of the Child the direct effect on Intention persists. This effect is, at least at first sight, unpredictable as its direction is inconsistent with the indirect effect Value of the Child-Intention. Whereas the direct effect shows a positive sign $(\beta=.23, p<.05)$, the indirect effect shows a negative one. Therefore, in this relation the Attitude variable assumes, more than a mediator function, a suppressor one as it changes the direction of the direct effect ${ }^{2}$. Nevertheless, the relation between Value of the Child and Intention is also explained through the effect of Attitude.

Thirdly, another indirect effect on Intention is the one from Behavior Experience. That variable does not have a direct effect, but rather an indirect effect mediated by other variables on the model: Behavioral Beliefs $(Z=2.26, \mathrm{p}<.05)$; Emotions $(\mathrm{Z}=2.63, \mathrm{P}<.05)$; and Subjective Norm $(Z=3.59, P<.05)$. No mediation effects were found for Normative and Behavior Control Beliefs. Nevertheless, the mediation effects suggest that the greater the worker's experience in proposing the residential care placement on neglected children, the more positive will be the emotions, the perception of consequences and of others approval, and the more positive will be worker's attitude towards that decision. Furthermore, those mediation effects rendered the direct effect of Behavior Experience on Attitude impossible.

\footnotetext{
2 "Suppression occurs when the indirect effect $a \times b$ has the opposite sign of the direct effect $c$ " (Shrout \& Bolger, 2002, p. 430).
} 
Therefore, to test the mediation effect of Attitude on the relation between Behavior

Experience and Intention, we ran a simplified version of the proposed model that did not consider the effect of the variables mediating Behavior Experience effect on Attitude. The analysis reveals a direct effect of Behavior Experience on Attitude $(\beta=.22, p<.05)$ and the Sobel test confirmed the mediation effect of Attitude on the relation of Behavior Experience on Intention $(Z=2.93, \mathrm{p}<.05)$.

\section{Discussion}

The decision to keep a child in the family or to put her in out-of-home placement following a case of parental maltreatment - has been characterized as complex, ambiguous and full of errors and uncertainty, especially in parental neglect cases (Beckett et al., 2007; Dickens, 2007; Rodrigues, 2012; Stowman \& Donohue, 2005).

The goal of this study was to test a model of the psychosocial process involved in the residential care placement decision of a neglected child, that takes into account both rational and intuitive theoretical approaches. Therefore, based on theoretical models of behavior and decision-making predictions widely studied in Social Psychology (Ajzen, 1985), a more integrative, dual and ecologic version of Theory of Planned Behavior's model was proposed for predicting the residential care placement decision of a neglected child.

The results revealed that the proposed model is the one that better fits the data and the one that contributes more to explain worker's motivation to propose the decision. Moreover, the absence of a direct relation between past behavior (Behavior Experience) and future behavior (Intention), has additionally proven the quality of the model as it suggests the sufficiency and efficacy of the variables included in the model to explain the behavior under study (Ajzen, 1991). More specifically, the study sustains that both rational and intuitive factors are involved in the workers' judgments. Rational information processing was evident 
in the effect of worker's beliefs about consequences of residential care and about the opinion of others from the professional context, personal networks and broader social context. The study also demonstrated the effect of more value-laden, affective and experiential variables, as well as behavior-specific variables. Before going into a more detailed discussion over each of the those variables, it is important to discuss one unexpected result: no reliable effect was found between Perceived Behavior Control (i.e. legal and organizational barriers and constraints to decision making) and worker's evaluation of and motivation to propose the residential care placement decision. In fact similar results found in other studies using Theory of Planned Behavior for predicting ethical decisions (Randall \& Gibson, 1991), suggest that it is due to the fact that when negative consequences may arise from the behavior/decision under study, it is less pertinent to think it will be predicted by the worker's lower or higher ability to control the behavior (Eagly \& Chaiken, 1993).

\section{Value of the child and value of the family}

This study demonstrates the presence of the value of the child and the value of the family variables on the decision making process over the residential care placement of a neglected child. Nevertheless, the process by which each of those values influence worker's judgment and the level of conflict they bring differs. First, only the value of the child directly predicts worker's motivation to propose the residential care placement of the neglected child. This indicates that the worker's motivation to prose that decision is positively predicted by the relevance attributed to child's interests and protection. Therefore, this result seems to be consistent with the principle of the 'Best Interest of the Child' mandated by the Portuguese law (Law n ${ }^{\circ}{ }^{\circ} 147 / 99$, art. 4..$^{\circ}$ Goldstein et al., 1996) and with the literature on the long term effects of parental neglect on child development (DePanfilis, 2006). The more the value attributed to child protection, the greater will be worker's motivation to propose the 
residential care placement of the child as a solution to keep the child away from parental neglect and, thus, to prevent further developmental injuries and to assure child protection and integrity. Secondly, as hypothesized based on the theoretical hierarchical relation ValueAttitude-Intention (Homer \& Kahle, 1988), both the value of the child and the value of the family have an effect on worker's motivation to propose that decision mediated by worker's Attitude effect. The interpretation of these mediation effects is the same: the more the worker values child protection/ family preservation, the more negative will be the evaluation of the pros and cons of the residential care placement as a social response for the neglected child, and the lower will be worker's motivation to propose that decision. On the one hand, these results are consistent with the literature on the negative impacts of residential care placement for both the child and the family (e.g., Johnson, Browne, \& Hamilton-Giachritsis,, 2006), as well as with studies that underline the workers' negative perceptions about the quality of residential care in Portugal (Torres et al., 1998). On the other hand, the direction of the mediated effect of the Value of the Child on Intention is somehow surprising as it is incongruent with the direct effect already mentioned. Therefore, this suggests that when the analysis controls for worker's evaluation of the positive and negative implications of placing the child in residential care, the direction of the effect of Value of the Child on Intention changes. This result, thus, indicates the presence of opposite forces in worker's judgment: one that favors the immediate positive effect of residential care to child protection keeping her away from the current source of danger (positive effect on intention); and another one that focus on residential care long-term effects for the child (negative effect as a result of the mediating role of Attitude). Therefore, the study proves the presence of a conflict in worker's judgment over a neglect case, and thus supports the presence of dilemmas and ambivalence that has been attributed to decision making over neglect cases, but until now without statistical confirmation (Beckett et al., 2007; Dickens, 2007). Furthermore, the results of this 
study demonstrate that the conflict does not occur between the value of the child and the value of the family as is usually thought (Besharov, 1985; Dickens, 2007; Goldstein et al., 1996), but rather within the value of the child, i.e. as a result of residential care contradictory implications for child protection and well-being both in short and in long term (Bullock et al., 1993; Casas, 1993; Johnson et al., 2006).

\section{Anticipated Emotions}

In this study worker's emotions effect on evaluation (Attitude) and motivation (Intention) to a residential care placement decision was always positive, i.e. the more positive the emotions that the worker anticipates to experience following the decision, the more favorable the evaluation of that decision and the higher the intention to defend it. Thus, this result not only supports the presence of an emotional dimension within the decisional process in child protection (Summers et al., 2012; Taylor et al., 2008), but it also builds on Summers and colleagues (2012) study: 1) it shows the specific effect of positive and negative Emotions; and 2) it shows the effect of emotions that are not immediately experienced at the time of the decision making, but that are anticipated to be experience once the decision is made (Loewenstein et al., 2001). Regarding the factors that predict the workers' emotions, this study proves the effect of socio-normative and behavioral factors. That is, the feelings the worker anticipates to experience are generally derived from past experience with this type of cases and from the impact that social influence carries to the worker. One could think then that this result translates the idea, often discussed in the literature, that social pressure has a relevant impact on the worker and on his/her actions, namely through fear that a wrong decision will cause recriminations and controversy at both organizational and social levels (e.g., Dickens, 2007; Kanani et al., 2002; Lachman, \& Bernard, 2006; Munro, 2005). 


\section{Behavior Experience}

Worker's experience in proposing the residential care placement of a neglected child positively affects worker's motivation to propose that decision through the mediation effect of the worker's positive evaluation about the implications of that social response. This result demonstrates, through the use of complex statistical tests, the overall idea in the literature that professional experience has an important role in decision making in child protection field (e.g., Davidson-Arad et al., 2003; Dickens, 2007; Lachman \& Bernard, 2006).

Nevertheless, it has to be noted that the majority of studies have operationalized that variable in terms of years of professional experience and not, as in this study, frequency of behavior. The frequency with which a worker proposes a social response, does not directly inform about the years of professional experience in the field. Nevertheless, additional analysis revealed a positive correlation between the two variables $(r=.210, p<.05)$, thus, contradicting the literature that have shown that workers with less years of experience have more probability to propose a residential care placement decision (Cash, 2001; Munro, 1999; Schuerman, Rossi, \& Budde, 1999; Davidson-Arad et al., 2003). Moreover, the analysis suggests that the effect of experience on worker's evaluation, and in turn in the intention to propose residential care, occurs through the effect of worker's previous experience with the consequences of that social response to the child (Behavioral Beliefs) and through the feelings and emotions the worker experienced in the past after a residential care placement decision, as well as on worker's previous perception about what people at work, family and friends think of the residential care placement of a neglected child (Subjective Norm). This idea had already been hypothesized in the literature (Davidson-Arad et al., 2003; Dickens, 2007; Kanani et al., 2002; Lachman, \& Bernard, 2006; Munro, 2005), but only now has received empirical support. 


\section{Risk Assessment}

Finally, concerning the role of risk assessment on worker's decision, first of all, the effect of this variable in the model, not only confirms the application of that legal and theoretical criteria on worker's judgment (Fallon et al., 2011; Law n¹47/99), but also shows that the level of risk/danger attributed to the neglect case was not consensual between participants and, thus, supports the complexity usually attributed to decision making towards this type of maltreatment cases (Beckett et al., 2007; Dickens, 2007). Secondly, it was demonstrated that, in decision making concerning neglect cases, the effect of risk assessment do not occurs directly on worker's intention to propose the residential care placement, but is rather mediated by worker's evaluation of that social response (i.e. Attitude). Using Slovic and collaborators (2005) terms, it can be stated that the reaction of workers to risk occurs more as an analysis and less as a kind of emotional reaction. More specifically, when the worker assesses the case as high risk/danger the judgment involves the evaluation of the residential care as a solution to the immediate protection of the child (Bullock et al., 1993; Kendrick, 2008), keeping the child away from the danger source - i.e. parental neglect at home - and its impacts on child development (DePanfilis, 2006). When the case is considered as low risk/danger the negative side of residential care placement - detrimental consequences to child physical, affective and social development (e.g., Johnson et al., 2006) - becomes more prevalent in worker's judgment.

\section{Conclusion}

This study allowed to overcome the lack of theoretically designed and empirically tested models to explain worker's decision to propose residential care placement (e.g., AradDavidzon \& Benbenishty, 2008). Moreover, it was possible to demonstrate that the worker, 
more than a determinant factor, is a preponderant factor of the decision making process, that integrates all other factors. This model can, therefore, be understood as a 'loupe glance' of the psychosocial process of the decision (threshold) involved in residential care placement.

The application of the 'psychosocial model of residential care placement' in this study revealed and supported the complexity and effort specifically involved in residential care placement decision in the context of a parental neglect case (Beckett et al., 2007; Dickens, 2007). The complexity in this study was evident in the: presence of multiple factors from different nature (emotional, experiential, cognitive, value-laden and normative); presence of conflict and ambivalence; presence of feelings and emotions; and in the presence of social influence processes that affect the emotional, attitudinal and motivational components of worker's judgment. These results not only sustain the view of decisions towards neglect cases as effortful, but also brings attention to the implications that all those forces and pressures might have in the worker's judgment and actions.

Therefore, it becomes urgent to develop training programs specifically focused on the multiple factors (e.g., social norms, emotions, cultural values, personal and professional experience) influencing judgment and decision in child protection. Professionals should be made aware of the factors that may be unconsciously influencing their decisions and should therefore be incited to examine themselves regarding the attitudes, values and beliefs that are sustaining their assessments and decision. The recognition of the factors and pressures involved might prevent biases and worker's defensive practices (Besharov, 1985; Dickens, 2007; Kanani et al., 2002; Lachman \& Bernard, 2006; Munro, 2005), as well as its consequences for the child (Iatrogenic Harm; Jones, 1991). To control the influence of individual attitudes, beliefs and values, the decision-making process has to become more and more collective. In order to assure that those decisions are a product of different professional and personal perspectives, workers must feel comfortable to freely express their opinions and 
concerns. The influence of others on workers' decision was quite evident in this study, thus pointing to the need to promote more democratic institutional and organizational work environments. Additionally, as social influence not only comes from close and direct relations with others (e.g., coworkers and superiors), but also from public opinion in general - namely through the media -, it would be important to promote a positive image of child protection services at the community level, which would increase the social recognition of state intervention on family as a mechanism that intends to promote and protect child well-being and integrity. This could, in turn, promote a better understanding of child protection and decrease the level of social criticism that exists towards child protection workers (Dickens, 2007; Kanani et al., 2002; Lachman, \& Bernard, 2006; Munro, 2005).

Other practical implication of this study should be to rethink some of the conflicts underlying decision making in child protection, as some of them may be fed by institutional and organizational issues like the quality of services/intervention provided at home and the quality of residential care. In this study the conflict in the decision-making process was related to the co-existence of an automatic response that considers residential care as the least detrimental alternative to immediately protect the child; and a more weighted response that includes one's perceptions and knowledge of that social response and its long term impacts on the child. The first response leads the worker to defend the residential care placement of the child, and the second leading to the opposite scenario. Therefore, it would be important to ensure at the institutional and political level, a redesign of child protection social responses in Portugal. The improvement in services and institutions (both in residential care, foster care and at-home interventions) could therefore prevent the child out-of-home placement, promote parents' rehabilitation and behavioral change, as well as change the impact of child protection system in children and increase the workers options when taking a decision. These improvements would likely change workers experiences regarding residential care placement 
and that, as suggested in this study results, could have an emotional and cognitive effect on worker's future decisions. Also, group sessions for child protection workers might be an opportunity to discuss and exchange experiences and perceptions, to deconstruct or resolve bad experiences, and also could promote a greater consistency of responses given to similar cases.

Besides the practical implications just discussed, the results of this study also pointed some theoretical implications. Studies like the one presented here will, hopefully, promote a new perspective in the study of decision making in child protection that not only considers the role of multiple determinant factors influencing decision making, but also benefits from theoretical and empirical knowledge on the more general decision-making topic that is lacking in nowadays research in the field of child protection (Baumann et al., 2011). Additionally, new studies are needed not only to prove the adequacy of the model for abuse cases, but also to test it with different target children (e.g., younger/older children) and towards other social responses (e.g, foster care). Also, international comparative studies are needed for the adequate generalization of these findings.

Without undermining this implications, some limitations of this study must be realized and addressed in future studies. This study is limited by the low participation rate $(15.5 \%)$, which may be related to worker's overload in child protection system in Portugal and, therefore, is consistent with other studies undertaken in Portugal with this population. Nevertheless, the data collection procedure might also have created some limitations. For ethical reasons related with worker's anonymity and imposed by the National Child and Youth Protection Committee, the data collection procedure ocurred through indirect contact. This lack of direct contact with workers - direct contact only occurred, via telephone, when the workers directly asked for additional debriefings - hindered the use of motivation strategies. This fact, not only might have reduced the number of participants, but also made it 
impossible to have a close control over the number of workers that received the study link and prevents us from having information about the specific unit each worker belonged to.

Nevertheless, based on the sociodemographic description of the sample, it can be verified that the study sample is quite diversified - in terms of country region, and also in terms of marital status, level and area of education, age and years of experience and, therefore, reduces the concerns related with sample representativeness.

For the same reasons, another limitation refers to the sample size. Although that could be a problem considering the complexity of the proposed model (with a set of 12 items and multiple paths), the analysis revealed good indexes of fit and significant effects. Also, the supplementary analysis using bootstrapping procedure provided the same results and, thus, rejects any type 2 error and confirms the reliability of the results.

A final concern regards the internal consistency of two of the measures (Perceived Behavior Control and Risk/Danger Assessment), which did not yield a satisfactory reliability (even though the other ten sets of items revealed high reliability). However, in Structural Equation Modeling analyses the concepts are defined as latent variables, thus, controlling for eventual measure errors.

Although acknowledging these limitations, the results of this study represent nevertheless one step further as its empirical evidences have both practical and theoretical implications, discussed above, thus providing cues to a rethinking of the child protection system and future research in this field.

\section{References}

Ajzen, I., \& Fishbein, M. (2005). The influence of attitudes on behavior. In D. Albarracin, T. J. Blair, \& M. P. Zanna (Eds.), The handbook of attitudes (Vol. 173, p. 221). New Jersey: Lawrence Erlbaum Associates, Inc. 
Ajzen, I. (1985). From intentions to actions: A theory of planned behavior. In J. Kuhi \& J. Beckmann (Eds.), Action control: From cognition to behavior (pp. 11.39). Heidelberg: Springer.

Ajzen, I. (1991). The theory of planned behavior. Organizational Behavior and Human Decision Processes, 50, 179-211.

Arad-Davidzon, B. \& Benbenishty. R. (2008). The role of workers' attitudes and parent and child wishes in child protection workers' assessments and recommendation regarding removal and reunification. Children and Youth Services Review, 30(1), 107-121.

Backe-Hansen, E. (2003) Justifying out-of-home placement: A multiple case study of decision-making in child welfare and protection services. IJCFW, 6 (4), 151-166.

Banach, M. (1998). The best interests of the child: decision-making factors. Families in Society. 79 (3), $331-340$.

Baumann, D.J., Dalgleish, L., Fluke, J., \& Kern, H.(2011).The decision-making ecology. Washington, DC: American Humane Association.

Beckett, C., McKeigue, B., \& Taylor, H. (2007). Coming to conclusions: social workers' perceptions of the decision-making process in care proceedings. Child \& Family Social Work, 12(1), 54-63.

Belsky, J. (1991). Psychological maltreatment: Definitional limitations and unstated assumptions. Development and Psychopathology, 3, 31-36.

Bentler, P. M. (1990). Comparative fit indexes in structural models. Psychological Bulletin, $107,238-246$.

Bentler, P. M., \& Bonett, D. G. (1980). Significance tests and goodness of fit in the analysis of covariance structures. Psychological Bulletin, 88, 588-606.

Besharov, D. J. (1985). Right vs. rights: The dilemma of child protection. Public Welfare, 43, $19-27$. 
Boldero, J., Moore, S., \& Rosenthal, D. (1992). Intentions, context, and safe sex: Australian adolescents' responses to AIDS. Journal of Applied Social Psychology, 22, 1374-1396.

Bollen, K.A. (1989). Structural Equations with Latent Variables. New York: John Wiley \& Sons, Inc.

Britner, P. A., \& Mossler, D. G. (2002). Professionals' decision-making about out-of-home placements following instances of child abuse. Child Abuse \& Neglect, 26, 317-332.

Bullock, R., Little, M., \& Millham, S. (1993). Residential Care for Children: A Review of the Research. London: HMSO.

Byrne, B. M. (2001). Structural equation modeling with AMOS: Basic concepts. Applications, and programming. Mahwah, NJ: Lawrence Erlbaum Associates, Inc.

Casas, F. (1993). Instituciones residenciales: ¿hacia donde? In Associación para la Prevención de los Malos Tratos en la Infancia (Ed.), III Congreso Estatal

Cash, S. J. (2001). Risk assessment in child welfare: The art and science. Children and Youth Services Review, 23, 811-830.

Castro, P., Garrido, M., Reis, E., \& Menezes, J. (2009). Ambivalence and conservation behaviour: An exploratory study on the recycling of metal cans. Journal of Environmental Psychology, 29(1), 24-33.

Cicchetti, D., \& Rizley, R. (1981). Developmental perspectives on the etiology, intergerational transmissions, and sequele of child maltreatment. New Directions for Child Development, 11, 31-55.

Conner, M., \& Armitage, J. (1998). Extending the Theory of Planned Behavior : A Review and Avenues for Further Research, Journal of Applied Social Psychology, 28, 14291464. 
Conner, M., \& Sparks, P. (2005). Theory of Planned Behaviour and Health Behaviour. In M. Conner \& P. Sparks (Eds.), Predicting health behaviour: Research and practice with social cognition models 2nd edition. (pp 170-222). Mainhead: Open University Press.

Dagleish. L. \& Drew E. (1989). The relationship of child abuse indicators to the assessment of perceived risk and the decision to separate. Child Abuse and Neglect, 13, $491-506$.

Dalgleish, L.I. (1988). Decision-making in child abuse cases: Applications of social judgment theory and signal detection theory. In B. Brehmer \& C. R. B. Joyce (Eds) Human Judgment: The SJT view. North Holland Elsevier.

Davidson-Arad, B., Englechin-segal, D., \& Wozner, Y. (2003). Short-term follow-up of children at risk : comparison of the quality of life of children removed from home and children remaining at home. Child Abuse \& Neglect, 27, 733-750. doi:10.1016/S01452134(03)00113-3

Davidson-Arad, B. (2009). Four Perspectives on the Quality of Life of Children at Risk Kept at Home and Removed from Home in Israel. British Journal of Social Work, 40(6), 1719-1735. doi:10.1093/bjsw/bcp099

DePanfilis, D. (2006). Child neglect: A guide for prevention, assessment, and intervention. Washington, DC: U.S. Department of Health and Human Services, Administration on Children and Families, Administration for Children, Youth, and Families, Children's Bureau, Office on Child Abuse and Neglect.

Dickens J. (2007). Child Neglect and the Law: Catapults, Thresholds and Delay. Child Abuse Review, 16, 77-92.

Eagly, A. H., and Chaiken, S. (1993). The Psychology of Attitudes. Fort Worth, TX: Harcourt Brace Jovanovich College Publishers. 
Fallon, B., Trocmé, N., \& MacLaurin, B. (2011). Should child protection services respond differently to maltreatment, risk of maltreatment, and risk of harm? Child abuse \& neglect, 35(4), 236-9. doi:10.1016/j.chiabu.2011.03.001

Feng, J.-Y. \& Wu, Y. M. (2005). Nurse's intention to report child abuse in Taiwan: A test of the theory of planned behavior. Research in Nursing \& Health, 28(4), 337-347.

Feng, J.-Y., Huang, T.-Y., \& Wang, C.-J. (2010). Kindergarten teachers' experience with reporting child abuse in Taiwan. Child Abuse \& Neglect, 34, 124-128.

Festinger, T. (1996). Going home and returning to foster care. Children and Youth Services Review, 18, 383-402.

Fialkov, M. J., \& Cohen, E. (1990). The mental health professional, the legal process, and the child in out-of-home care. In P. V. Grabe (Ed.), Adoption resources for mental health professionals (pp. 189-202). New Brunswick, NJ: Transaction Publishers.

Gerrard, M., Gibbons, F. X., Houlihan, A. E., Stock, M. L., \& Pomery, E. A. (2008). A dualprocess approach to health risk decision making: The prototype willingness model. Developmental Review, 28, 29-61.

Godin, G., \& Kok, G. (1996). The theory of planned behavior: A review of its applications in health-related behaviors. American Journal of Health Promotion, 11, 87-98.

Gold, N., Benbenishty, R.,\& Osmo, J. (2001). A comparative study of risk assessment and recommended interventions in Canada and Israel. Child Abuse and Neglect, 25(5), $607-622$.

Goldstein, J., Solnit, A., Goldstein \& Freud, A. (1996). The best interest of the child. New York: The Free Press.

Hammond, K. R. (1996). Human judgment and social policy. New York: Oxford University Press.

Homer, P. \& Kahle, L. (1988). A structural equation test of the 'Value-Attitude-Behaviour' 
Hierarchy. Journal of Personality and Social Psychology 54, 638-64.

Hu, L., \& Bentler, P. M. (1998). Fit indices in covariance structure modeling: Sensitivity to under-parameterized model misspecification. Psychological Methods, 3, 424-453.

Humphreys, J. \& Ramsey, A. (1993). Child Abuse. In J. Campbell e J. Humphreys (Eds.). Nursing Care of Survivors of Family Violence (2 $2^{\mathrm{a}}$ ed.). St. Louis: Mosby.

Instituto da Segurança Social, IP. (2012). CASA-2011 Relatório de Caracterização Anual da Situação do Acolhimento das Crianças e Jovens: Centro de Acolhimento Temporário. Lisboa: ISS, IP.

Jagannathan, R., \& Camasso, M. J. (1996). Risk assessment in child protective services: a canonical analysis of the case management function. Child Abuse \& Neglect, 20, 599612.

Johnson, R., Browne, K., \& Hamilton-Giachritsis, C. (2006). Young children in institutional care at risk of harm. Trauma, violence \& abuse, 7(1), 34-60.

Jones, D. P. (1991). Professional and clinical challengers to protection of children. Child Abuse \& Neglect, 15, 57-66.

Kanani, K., Regehr, C. \& Bernstein, M.M. (2002). Liability considerations in child welfare: Lessons from Canada. Child Abuse and Neglect, 26, 1029-1043.

Kendrick, A. (Ed.) (2008). Residential child care: Prospects and challenges. Research Highlights Series. London: Jessica Kingsley.

Kenny, M. C. (2001). Child abuse reporting: Teachers' perceived deterrents. Child Abuse and Neglect, 25, 81-92.

Kline, R.B. (2005). Principles and Practice of Structural Equation Modeling (2nd Edition ed.). New York: The Guilford Press.

Lachman, P. \& Bernard, C. (2006). Moving from blame to quality: how to respond to failures in child protective services. Child Abuse \& Neglect, 30, 963-968. 
Law for the Protection of at-risk Children and youth - Law n. ${ }^{\circ} 147 / 99$.

Lindsey, D. (1991). Factors Affecting the Foster Placement Decision: An Analysis of the National Survey data. American Journal of Orthopsychiatry, 61(2), 272-281.

Little, M., Axford, N. \& Morpeth, L. (2004). Risk and protection in the context of services for children in need. Child and Family Social Work, 9 (1), 105-118.

Loewenstein, G., Weber, E. U., Hsee, C. K., \& Welch, N. (2001). Risk as feelings. Psychological Bulletin, 127, 267-286.

Milfont, T. L., Duckitt, J., \& Wagner, C. (2010). A Cross-Cultural Test of the value-attitudebehavior hierarchy. Journal of Applied Social Psychology, 40(11), 2791-2813.

Munro, E. (1999). Common errors of reasoning in child protection. Child Abuse \& Neglect, $23,745-758$.

Munro, E. (2005). Improving pratice: child protection as a system's problema. Children and Youth Services Review, 27, 375 - 391.

Oreg, S., \& Katz-Gerro, T. (2006). Predicting Proenvironmental Behavior Cross-Nationally: Values, the Theory of Planned Behavior, and Value-Belief-Norm Theory. Environment and Behavior, 38, 462-483.

Parton, N. (2010). From dangerousness to risk: The growing importance of screening and surveillance systems for safeguarding and promoting the well-being of children in England. Health, Risk \& Society, 12(1), 51-64.

Peters, D. F. (2001). Examining Child Sexual Abuse Evaluations: The types of information affecting expert judgment. Child Abuse \& Neglect, 25, 149-178.

Portwood, S. G. (1998). The impact of individuals' characteristics and experiences on their definitions of child maltreatment. Child Abuse \& Neglect, 22, 437-452. 
Randall, D. M., \& Gibson, A. M. (1991). Ethical decision making in the medical profession: An application of the theory of planned behavior. Journal of Business Ethics, 10, 111122.

Rodrigues, L. (2012). The application of Promotion and Protection Measures to at-riskdanger children: Psychosocial Context of Decision-Making (Unpublished Doctoral dissertation thesis). University Institute of Lisbon - ISCTE, Lisbon.

Rossi, P.H., Schuerman, J., \& Budde, S. (1999). Understanding decisions about child matreatment. Evaluation Review, 23(6): 579-98.

Rzepnicki, T. L., \& Johnson, P. R. (2005). Examining decision errors in child protection: A new application of root cause analysis. Children and Youth Services Review,27(4), 393407.

Schuerman, J., Rossi, P. H., \& Budde, S. (1999). Decision on placement and family preservation. Evaluation Review, 23(6), 599-618.

Schwalbe, C. (2004). Re-visioning risk assessment for human service decision making. Children and Youth Services Review, 26(6), 561-576.

Shemmings, D. (2000). Professionals' attitudes to children's participation in decision-making: dichotomous positions and doctrinal contests. Child and Family Social Work, 5 (3), $235-244$.

Slovic, P., Peters, E., Finucane, M.L., \& MacGregor, D.G. (2005). Affect, Risk, and decision making. Health Psychology, 24(4), S35-S40.

Stowman, S. \& Donohue, B. (2005). Assessing child neglect: A review of standardized measures. Aggression and Violent Behavior: A Review Journal, 10, 491-512.

Sullivan, C., Whitehead, P.C. Leschied, A.W., Chiodo, D. \& Hurley, D. (2008). Perception of Risk Among Child Protection Workers. Children and Youth Services Review. 30 (7), 699-704. 
Summers, A., Gatowski, S., \& Dobbin, S. (2012.). Terminating parental rights : the relation of judicial experience and expectancy-related factors to risk perceptions in child protection cases. Psychology, Crime and Law, 18(1), 95-112.

Taylor, H., Beckett, C. \& McKeigue, B. (2008) Judgments of Solomon: anxieties and defences of social workers involved in care proceedings. Child and Family Social Work, $13,23-31$.

Tetlock , P. E. (1986). Integrative complexity of policy reasoning. In S. Kraus \& R. Perloff (Eds.), Mass media and political thought. Beverly Hills: Sage.

Tilbury, C., \& Osmond, J., (2006). Permanency Planning in Foster Care: A Research Review and Guidelines for Practitioners. Australian Social Work, 59(3), 265-280.

Torres, A. (Coord), Pegado, E., Sarmento, M., Hilário, A., Freitas, A., Sousa, I., Cruz, R., \& Penha, A., (2008). Estudo de Diagnóstico e Avaliação das Comissões de Protecção de Crianças e Jovens: Relatório Final. Lisboa.

Weber, E. U., \& Johnson, E. J. (2009). Mindful judgment and decision making. Annual review of psychology, 60, 53-85.

Zuravin, S. J., \& DePanfilis, D. (1997). Factors affecting foster care placement of children receiving child protective services. Social Work Research, 21, 34-42. 
Figure 1. Proposed Model of the psychosocial process underlying the out-of-home placement in Residential care decision-making for parental neglect cases

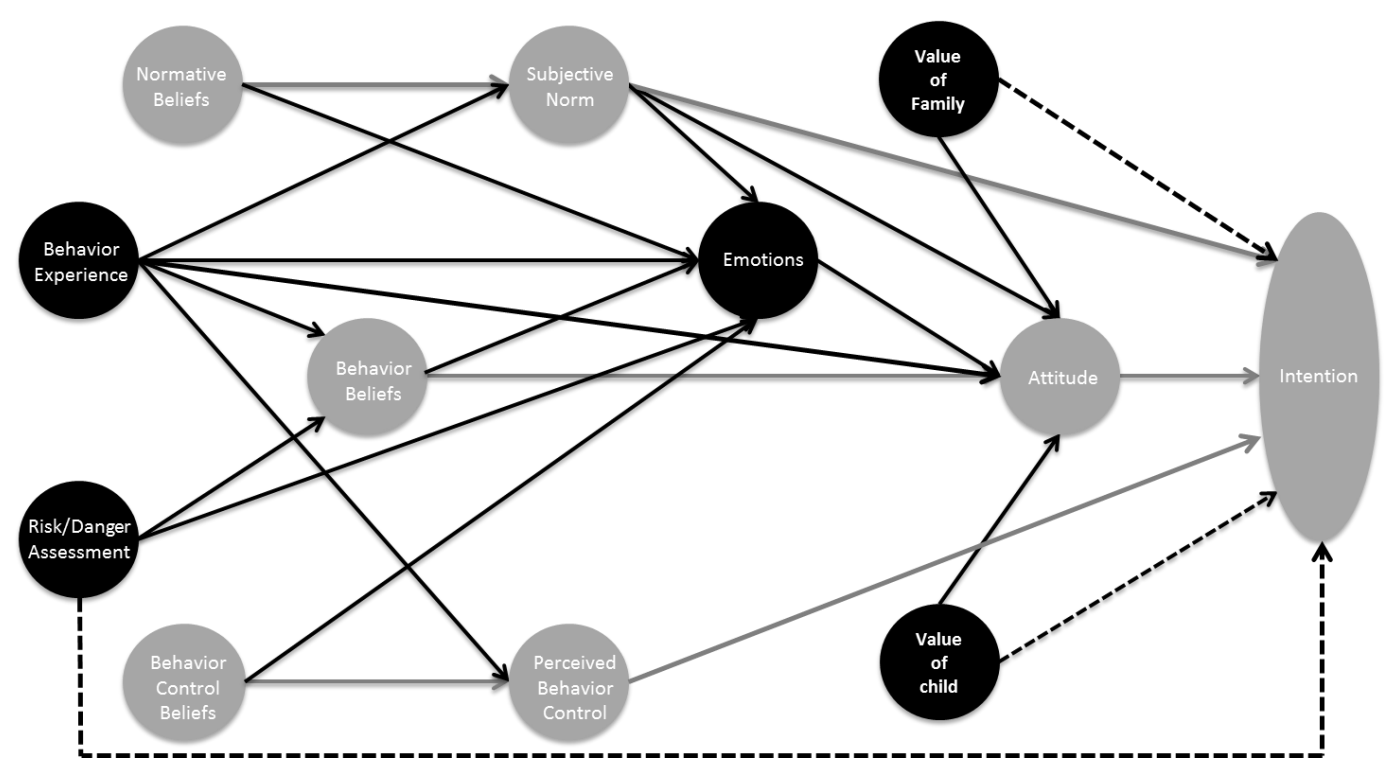

--- Direct effects; __ Mediation effects

Variables and arrows in grey correspond to TPB's model; variables and arrows in black correspond to new variables and relations added to TPB's model

Figure 2. Vignette of a fictitious neglect case

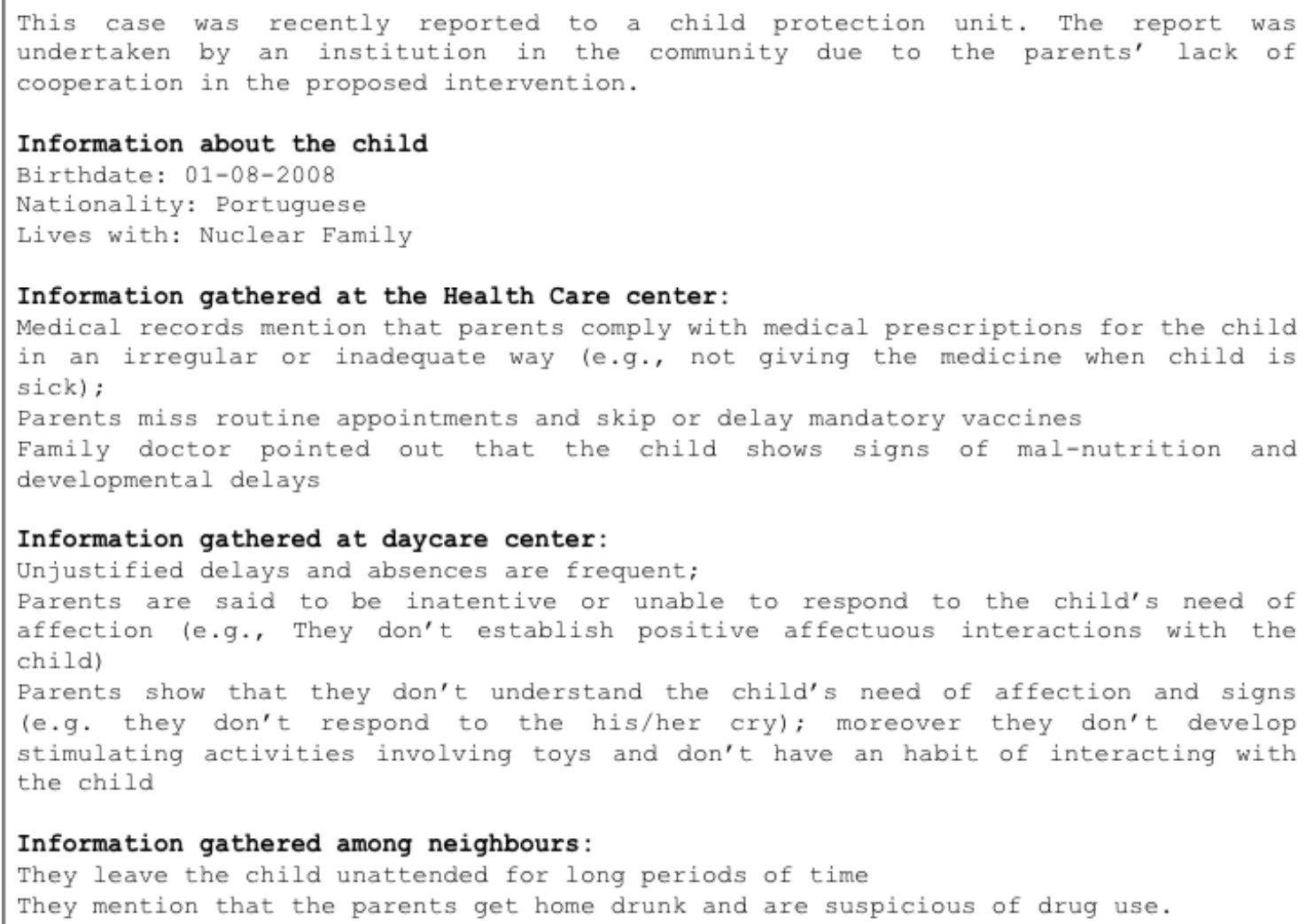


Figure 3. Psychosocial decision-making model of out-of-home placement in residential care for parental neglect cases

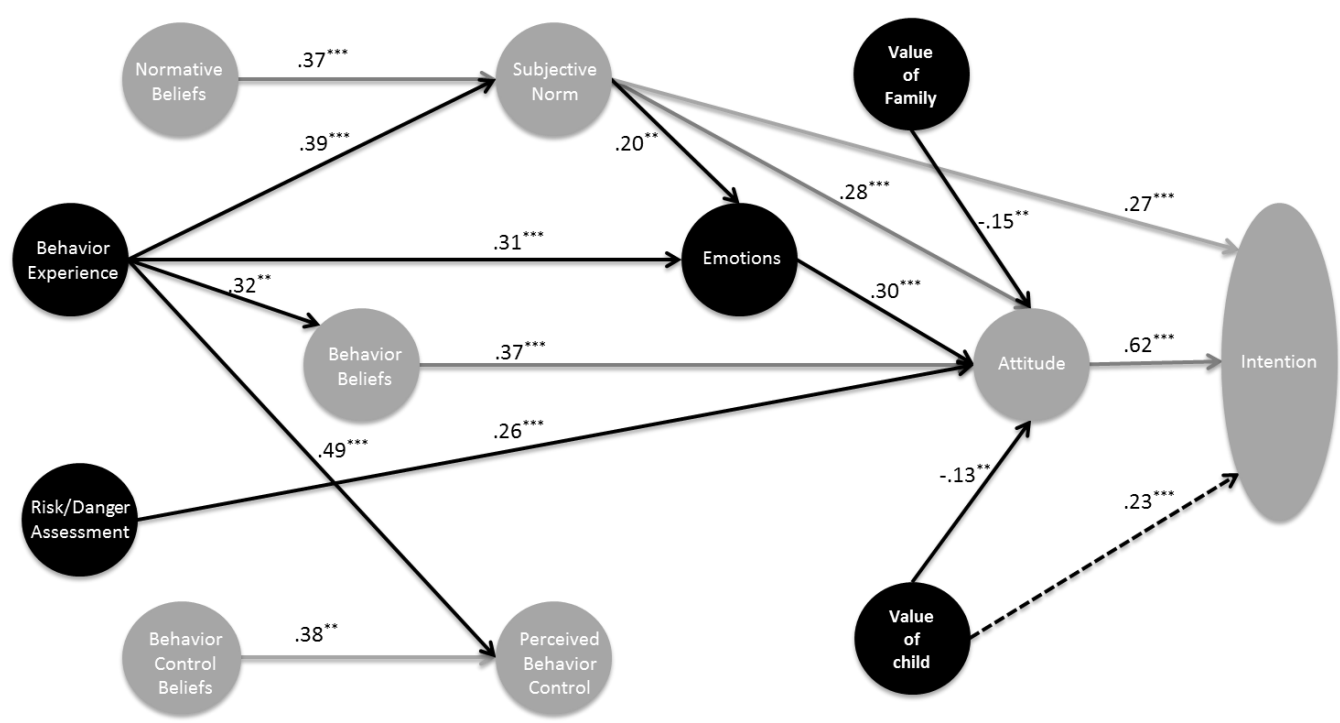

--- Direct effects; __ Mediation effects

Variables and arrows in grey correspond to TPB's model; variables and arrows in black correspond to new variables and relations added to TPB's model 
Table 1. Demographic characteristics of the sample

\begin{tabular}{|c|c|c|c|}
\hline Characteristics & $\mathbf{N}$ & Description & Percentage \\
\hline Gender & 144 & $\begin{array}{l}\text { Female } \\
\text { Male }\end{array}$ & $\begin{array}{l}84.7 \\
15.3\end{array}$ \\
\hline Marital Status & 144 & $\begin{array}{l}\text { Single/divorced/widowed } \\
\text { Married/live together }\end{array}$ & $\begin{array}{l}26.4 \\
73.6\end{array}$ \\
\hline Education & 142 & $\begin{array}{l}\text { Diploma/Baccalaureate } \\
\text { Degree } \\
\text { College Degree } \\
\text { Master's Degree/PhD }\end{array}$ & $\begin{array}{l}4.9 \\
83.1 \\
12.0\end{array}$ \\
\hline $\begin{array}{l}\text { Area of } \\
\text { Education }\end{array}$ & 141 & $\begin{array}{l}\text { Education } \\
\text { Psychology } \\
\text { Health } \\
\text { Social Work } \\
\text { Languages } \\
\text { Law } \\
\text { Other Social Sciences } \\
\text { Other }\end{array}$ & $\begin{array}{c}12.1 \\
22.0 \\
7.1 \\
32.6 \\
6.4 \\
3.5 \\
10.6 \\
5.7\end{array}$ \\
\hline Unit Location & 138 & $\begin{array}{l}\text { North } \\
\text { Center } \\
\text { Lisbon } \\
\text { South } \\
\text { Archipelagos }\end{array}$ & $\begin{array}{l}18.1 \\
32.6 \\
19.4 \\
18.8 \\
11.1\end{array}$ \\
\hline Characteristics & $\mathbf{N}$ & Mean & $S D$ \\
\hline Mean age & 144 & 38.4 & 9.20 \\
\hline Number of Children & 144 & 1.17 & 1.03 \\
\hline Years of experience & 144 & 14.14 & 9.38 \\
\hline $\begin{array}{l}\text { Years of experience } \\
\text { in child protection } \\
\text { units }\end{array}$ & 144 & 4.03 & 3.20 \\
\hline
\end{tabular}


Table 2. Matrix of Proposed model latent variables' variances and covariances

Intention1 Intention2 Attitude1 Attitude2 SubjNorm1 SubjNorm2 SubjNorm3 PercBehav PercBehav Emotion1 Emotion2 Emotion3 Emotion4 Behav Value Value Behavior Behavior Normative Normative Normative BehControl BehControl RiskDanger

\begin{tabular}{|c|c|c|c|c|c|c|c|c|c|c|c|c|c|c|c|c|c|c|c|c|c|c|c|c|}
\hline & Intention1 & tention2 & trffuder & Attfude2 & 1bjNormi & ubj]Norm? & 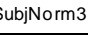 & Controlt & Control2 & Emotion1 & & motion3 & Emotion4 & Experience & Family & Child & Belief1 & Belief2 & Belief1 & Belief2 & Belief3 & Belief1 & Belief2 & Assess \\
\hline Intention1 & 1 & & & & & & & & & & & & & & & & & & & & & & & \\
\hline Intention2 & 0,772 & 1 & & & & & & & & & & & & & & & & & & & & & & \\
\hline Attitude1 & 0,605 & 0,508 & 1 & & & & & & & & & & & & & & & & & & & & & \\
\hline Attitude2 & 0,593 & 0,539 & 0,821 & 1 & & & & & & & & & & & & & & & & & & & & \\
\hline SubjNorm1 & 0,512 & 0,444 & 0,459 & 0,418 & 1 & & & & & & & & & & & & & & & & & & & \\
\hline SubjNorm2 & 0,521 & 0,432 & 0,496 & 0,484 & 0,742 & 1 & & & & & & & & & & & & & & & & & & \\
\hline SubjNorm3 & 0,546 & 0,468 & 0,432 & 0,446 & 0,787 & 0,828 & 1 & & & & & & & & & & & & & & & & & \\
\hline $\begin{array}{l}\text { PercBehav } \\
\text { Control_1 }\end{array}$ & 0,306 & 0,283 & 0,267 & 0,285 & 0,334 & 0,333 & 0,285 & 1 & & & & & & & & & & & & & & & & \\
\hline $\begin{array}{l}\text { PercBehav } \\
\text { Control2 }\end{array}$ & 0,249 & 0,157 & 0,375 & 0,34 & 0,318 & 0,293 & 0,302 & 0,432 & 1 & & & & & & & & & & & & & & & \\
\hline Emotions1 & 0,307 & 0,3 & 0,385 & 0,453 & 0,298 & 0,357 & 0,308 & 0,225 & 0,333 & 1 & & & & & & & & & & & & & & \\
\hline Emotions2 & 0,175 & 0,163 & 0,319 & 0,302 & 0,112 & 0,216 & 0,196 & 0,125 & 0,249 & 0,634 & 1 & & & & & & & & & & & & & \\
\hline Emotions3 & 0,125 & 0,102 & 0,305 & 0,301 & 0,164 & 0,249 & 0,166 & 0,218 & 0,263 & 0,523 & 0,441 & 1 & & & & & & & & & & & & \\
\hline Emotions 4 & 0,342 & 0,283 & 0,48 & 0,438 & 0,198 & 0,297 & 0,179 & 0,2 & 0,358 & 0,639 & 0,66 & 0,47 & 1 & & & & & & & & & & & \\
\hline $\begin{array}{l}\text { Behavior } \\
\text { Experience }\end{array}$ & 0,431 & 0,339 & 0,456 & 0,488 & 0,41 & 0,407 & 0,394 & 0,366 & 0,346 & 0,391 & 0,308 & 0,232 & 0,292 & 1 & & & & & & & & & & \\
\hline ValueFamily & $-0,052$ & $-0,001$ & $-0,203$ & $-0,199$ & $-0,017$ & $-0,1$ & $-0,04$ & $-0,019$ & $-0,025$ & $-0,054$ & $-0,052$ & 0,008 & $-0,157$ & $-0,053$ & 1 & & & & & & & & & \\
\hline ValueChild & 0,215 & 0,225 & $-0,048$ & $-0,037$ & 0,144 & 0,14 & 0,206 & 0,163 & $-0,047$ & $-0,057$ & $-0,064$ & $-0,036$ & $-0,087$ & 0,01 & 0,038 & 1 & & & & & & & & \\
\hline $\begin{array}{c}\text { Behavior } \\
\text { Belief1 }\end{array}$ & 0,347 & 0,303 & 0,408 & 0,487 & 0,311 & 0,272 & 0,298 & 0,252 & 0,233 & 0,202 & 0,15 & 0,231 & 0,262 & 0,273 & $-0,027$ & 0,126 & 1 & & & & & & & \\
\hline $\begin{array}{l}\text { Behavior } \\
\text { Belief2 }\end{array}$ & $-0,082$ & 0,117 & $-0,065$ & $-0,082$ & $-0,006$ & $-0,078$ & $-0,013$ & $-0,078$ & 0,058 & 0,022 & 0,068 & $-0,033$ & 0,038 & $-0,1$ & 0,079 & $-0,114$ & $-0,305$ & 1 & & & & & & \\
\hline $\begin{array}{c}\text { Normative } \\
\text { Belief1 }\end{array}$ & 0,258 & 0,335 & 0,259 & 0,23 & 0,355 & 0,376 & 0,317 & 0,334 & 0,153 & 0,195 & 0,124 & 0,039 & 0,225 & 0,199 & $-0,071$ & 0,107 & 0,265 & $-0,007$ & 1 & & & & & \\
\hline $\begin{array}{c}\text { Normative } \\
\text { Belief2 }\end{array}$ & 0,203 & 0,298 & 0,098 & 0,083 & 0,283 & 0,194 & 0,301 & 0,771 & 0,156 & 0,139 & $-0,001$ & $-0,06$ & 0,042 & 0,055 & 0,131 & 0,077 & 0,12 & 0,136 & 0,388 & 1 & & & & \\
\hline $\begin{array}{c}\text { Normative } \\
\text { Belief3 }\end{array}$ & 0,237 & 0,345 & 0,142 & 0,12 & 0,342 & 0,304 & 0,338 & 0,221 & 0,205 & 0,198 & 0,109 & 0,113 & 0,148 & 0,123 & 0,117 & 0,101 & 0,216 & 0,071 & 0,605 & 0,617 & 1 & & & \\
\hline $\begin{array}{c}\text { BehavControl } \\
\text { Belief1 }\end{array}$ & 0,086 & 0,182 & 0,064 & 0,077 & 0,048 & $-0,044$ & 0,083 & 0,16 & 0,055 & 0,083 & 0,128 & $-0,009$ & 0,051 & 0,122 & 0,08 & 0,102 & $-0,03$ & 0,136 & 0,127 & 0,024 & 0,1 & 1 & & \\
\hline $\begin{array}{l}\text { BehavControl } \\
\text { Belief2 }\end{array}$ & $-0,035$ & 0,007 & 0,106 & 0,032 & 0,057 & $-0,008$ & $-0,018$ & 0,225 & 0,175 & $-0,018$ & $-0,058$ & 0,046 & $-0,017$ & 0,065 & $-0,144$ & 0,094 & 0,113 & $-0,053$ & 0,242 & $-0,012$ & 0,064 & 0,362 & 1 & \\
\hline $\begin{array}{c}\text { RiskDanger } \\
\text { Assess }\end{array}$ & 0,286 & 0,22 & 0,382 & 0,41 & 0,282 & 0,159 & 0,171 & 0,067 & 0,227 & 0,004 & 0,047 & 0,013 & $-0,003$ & 0,285 & $-0,03$ & 0,057 & 0,191 & $-0,093$ & 0,178 & 0,122 & 0,213 & 0,003 & 0,157 & 1 \\
\hline Mean & 1,28 & 1,05 & 1,6 & 1,62 & 1,41 & 1,53 & 1,21 & 1,33 & 1,28 & 0,61 & $-0,1$ & 0,56 & 0,49 & 4,63 & 2,42 & 5,93 & 5,97 & 3,03 & 5,89 & 5,27 & 5,55 & 3,66 & 5,65 & 10,3 \\
\hline$S D$ & 1,75 & 1,96 & 1,61 & 1,51 & 1,46 & 1,45 & 1,51 & 1,49 & 1,58 & 1,7 & 1,73 & 1,85 & 1,67 & 1,73 & 1,62 & 1,59 & 0,81 & 0,7 & 0,74 & 0,83 & 0,9 & 0,99 & 0,94 & 1,88 \\
\hline
\end{tabular}


Table 3. Comparison of the Proposed model (Hyp. Model) and the model of the Theory of Planned Behavior (TPB model)

\begin{tabular}{lccccccccc}
\hline & $\chi^{2}$ & gl & $\chi^{2} / \mathbf{g l}$ & CFI & GFI & AGFI & RMSEA & St RMR & $\mathbf{R}^{2}$ \\
\hline Hyp. Model & 417.1 & 218 & 1.91 & .905 & .857 & .803 & .069 & 0.079 & .61 \\
TPB Model & 644,8 & 242 & 2.66 & .807 & .784 & .732 & .093 & 0.170 & .47 \\
\hline
\end{tabular}

